\title{
Organic fertilizer source and application method impact ammonia volatilization
}

\begin{abstract}
Ammonia (NH3) volatilization from fertilizer applications reduces efficiency and poses environmental hazards. This study used semi-open static chambers to measure NH3 volatilization from organic fertilizers (feather meal, blood meal, fish emulsion, cyanofertilizer) to evaluate the impacts of fertilizer source, application method, and rate on $\mathrm{NH} 3$ volatilization. In 2014, two application rates (28 and $56 \mathrm{~kg} \mathrm{~N}$ ha-1) were applied to lettuce (Lactuca sativa L.). Solid fertilizers (feather meal, blood meal) were preplant applied in a subsurface band, whereas liquid fertilizers (fish emulsion, cyano-fertilizer) were applied weekly through drip irrigation beginning two weeks after transplanting. In 2015, a single application rate (28 kg N ha-1) was applied to cucumber (Cucumis sativus L.). Solid fertilizers were applied in either subsurface or surface bands. There was a significant difference in NH3 volatilization among fertilizers, but there was little difference between application rates. Liquid fertilizers had lower NH3 emissions than solid fertilizers due to their timing and placement. In 2014 , blood meal at $56 \mathrm{~kg} \mathrm{~N}$ ha-1 and feather meal at both rates had the highest NH3 fluxes. In 2015, surface-banded blood and feather meal had the highest NH3 fluxes. Fertilizer decisions for organic systems should consider NH3 emission losses and practices for their reduction.
\end{abstract}

Keyword: Ammonia volatilization; Organic fertilizer; Application method 